\title{
The parasitoid species complex associated with sexual and parthenogenetic Naryciinae (Lepidoptera: Psychidae): Integrating ecological and molecular analyses
}

\author{
Jelmer A. ELZINGA ${ }^{1}$, Kees ZWAKHALS ${ }^{2}$, Johanna MAPPES ${ }^{1}$ and Alessandro GRAPPUTO ${ }^{3}$ \\ ${ }^{1}$ Centre of Excellence in Evolutionary Research, Department of Biological and Environmental Science, P.O. Box 35, \\ 40014 University of Jyväskylä, Finland; e-mails: jelmerelzinga@hotmail.com, johanna.mappes@jyu.fi \\ ${ }^{2}$ Dr. Dreeslaan 204, 4241 CM Arkel, The Netherlands; e-mail: keeszwakhals@yahoo.com \\ ${ }^{3}$ Department of Biology, University of Padua, Via Ugo Bassi 58/B, I-35121 Padua, Italy; e-mail: alessandro.grapputo@unipd.it
}

Key words. Barcoding, larval remains, parasitism, parthenogenesis, sex ratio, COI, COII, Wingless, Hymenoptera, Braconidae, Ichneumonidae, Lepidoptera, Psychidae, Naryciinae

\begin{abstract}
This study describes the parasitoid species complex associated with seven closely related species of sexual (Siederia rupicollella, S. listerella, Dahlica lazuri, D. charlottae and D. lichenella) and parthenogenetic (Dahlica fennicella and D. triquetrella) Naryciinae (Lepidoptera: Psychidae) in Central Finland. A thorough ecological analysis of all the species of parasitoids recorded was combined with analyses of molecular data. Mitochondrial and nuclear DNA data were obtained from all the species in order to (1) detect cryptic species associated with host specialization, (2) assign undescribed males to females, and (3) verify the morphological identification of closely related species. A DNA barcoding technique was employed to identify host species from parasitized larval remains. By sampling more than 10,000 host larvae, of which $25.7 \%$ were parasitized, nine parasitoid species were identified morphologically, including both koinobionts (Ichneumonidae: Diadegma incompletum, Macrus parvulus, Trachyarus borealis, T. solyanikovi, T. fuscipes, T. brevipennis and Braconidae: Meteorus affinis) and idiobionts (Ichneumonidae: Orthizema flavicorne, Gelis fuscicornis). Ecological characteristics such as time and mode of host attack, time of emergence and level of specialization differed widely. The results show that differences in parasitoid biology need to be taken into account when studying differences in percentage parasitism of sexual and parthenogenetic Naryciinae. The molecular data revealed that one parasitoid species M. parvulus may consist of two cryptic forms associated with the sexual and parthenogenetic hosts, respectively. The data further establishes that $T$. brevipennis and some T. fuscipes are in fact morphotypes of one species. The large variation in mitochondrial DNA within species and its inconsistency with nuclear DNA demonstrate that current species and genus delimitation is inadequate in the Trachyarus species group. Our study shows that it is essential to use DNA barcoding methods when investigating host-parasitoid complexes.
\end{abstract}

\section{INTRODUCTION}

Variation in reproductive mode makes the bagworm moths of the subfamily Naryciinae (Lepidoptera: Psychidae) an extremely interesting group for studying the consequences of sexual and parthenogenetic reproduction. Although very rare within Lepidoptera, obligate parthenogenetic reproduction has evolved independently several times in the Naryciinae (Grapputo et al., 2005). In theory, parthenogenetic species should replace their closelyrelated sexual species in the short term since they do not have the costs of producing males, do not experience the risks associated with mating and should colonize new areas more easily. Still, species of both types co-occur in many places, and even, on occasion, both types of the same species (Lepidopterologen-Arbeitsgruppe, 1997; Kumpulainen et al., 2004).

A 2004 study in Finland that measured parasitism of Naryciinae over a period of 3 years found that parasitism was higher in places where sexual species were predominant (Kumpulainen et al., 2004). The authors suggest that this correlation potentially reflects "the parasite hypothesis of sex" (i.e., the Red Queen hypothesis, see, a. o., King et al., 2009), which posits that genetically more variable sexuals tolerate parasites better than asexuals. Alternatively, if parasitoids preferentially attack parthenogenetic forms, they could maintain the presence of sexuals. Unfortunately, in the study by Kumpulainen et al. (2004) the parasitoids were not identified nor was their biology known, although it was noted that a range of species were involved. Therefore, the mechanism causing the differences in parasitism rates was not identified.

The main purpose of this paper is to describe the parasitoid species complex associated with sexual and parthenogenetic Naryciinae larvae in order to carry out a more detailed analysis of the differences in percentage parasitism recorded for sexual and parthenogenetic Naryciinae. This study was conducted at 70 different sites in Central Finland, where more than 10,000 host larvae were collected. To test for specialization on parthenogenetic or sexual hosts, host species were identified by sequencing a fragment of the COII mitochondrial DNA from the larval host remains.

Knowledge of potentially cryptic species is essential to understanding host-parasitoid interactions in multi-host communities (Kankare et al., 2005). In several species of parasitoids the existence of cryptic species - associated with host specialization - has been established through 
molecular analysis (Kankare et al., 2005; Smith et al., 2007; Bernardo et al., 2008). Moreover, it is clear that taxonomy based on morphology alone may lead to different results than those based on molecular analyses, partly due to unclear and vague descriptions in some groups. Therefore, molecular analyses of parasitoid mitochondrial and nuclear DNA were performed in order to (1) test for potential host-specific cryptic species, (2) reliably assign male parasitoids to species, and (3) verify the morphological identification of closely related species.

\section{MATERIAL AND METHODS}

\section{Collection and rearing}

In February 2008, before bagworm moth larvae became active, 71 forested sites around Jyväskylä, Central Finland were selected (Fig. 1). At each site (separated from each other by at least $500 \mathrm{~m}$ ) tape (TRENDtape, Müroll, Frastanz, Austria) was attached, adhesive side outwards, around 10-25 (average $15.9 \pm 0.7$ s.e.) of the larger trees, approximately $1.5 \mathrm{~m}$ above the ground. The maximum distance between trees within a site was $100 \mathrm{~m}$. All Naryciinae larvae, climbing up trees with their cases to pupate, that were trapped by the tape were collected. A total of 1132 trees (82\% Picea, 13\% Betula, 3\% Pinus, 1\% Populus) were sampled. In addition, immature larvae were collected throughout the year from some sites and reared on mosses and lichen in pots until autumn. Although survival was low, some parasitoids emerged from these larvae.

From 15 March each site was visited once a week until the beginning of May (total: 9 weeks), after which almost no mature larvae were found. Each week, all the mature larvae caught by the tape were collected and placed in individual rearing tubes within three days of collection: these were placed inside a growth cabinet at $10 / 20^{\circ} \mathrm{C}(16 / 8 \mathrm{~h}$ cycle $)$ and $85 \%$ humidity. A minority were kept at $5^{\circ} \mathrm{C}$ for up to 3 weeks due to space and time constraints. From the beginning of July to the beginning of September, the temperature was set at $15 / 25^{\circ} \mathrm{C}(16 / 8 \mathrm{~h}$ cycle $)$ to approximate summer conditions. At the beginning of October, the temperature was set at a constant $4^{\circ} \mathrm{C}$ for 5 months to imitate winter conditions. The dark/light cycle in the growth cabinet was adjusted regularly to outside conditions throughout the year.

All tubes were checked for the emergence of moths or parasitoids every day, and each emerged individual was placed in $99 \%$ alcohol for preservation. No parasitoids or moths emerged after the "winter" treatment. Dissecting a random subsample (n $=42$ ) of the cases from which nothing emerged revealed that they were either empty or contained a dead bag worm larva or pupa. If a parasitoid emerged we collected, if present, the remains of the host larva (mainly skin) and preserved it in $99 \%$ ethanol.

\section{Identification}

Parasitoid species were separated based on their morphology. Several parasitoid individuals of each type were sent to specialists for identification: Klaus Horstmann identified specimens of Diadegma and Macrus, Martin Schwarz Gelis and Orthizema, and Kees van Achterberg braconids. The Trachyarus were identified by Kees Zwakhals. Morphological identification of males was not possible for most species due to the absence of descriptions or a lack of distinguishing characteristics. However, the males were assigned to species by means of a DNA-analysis Specimens of each species, including those genetically analysed, are deposited in the collections of the respective identifiers.

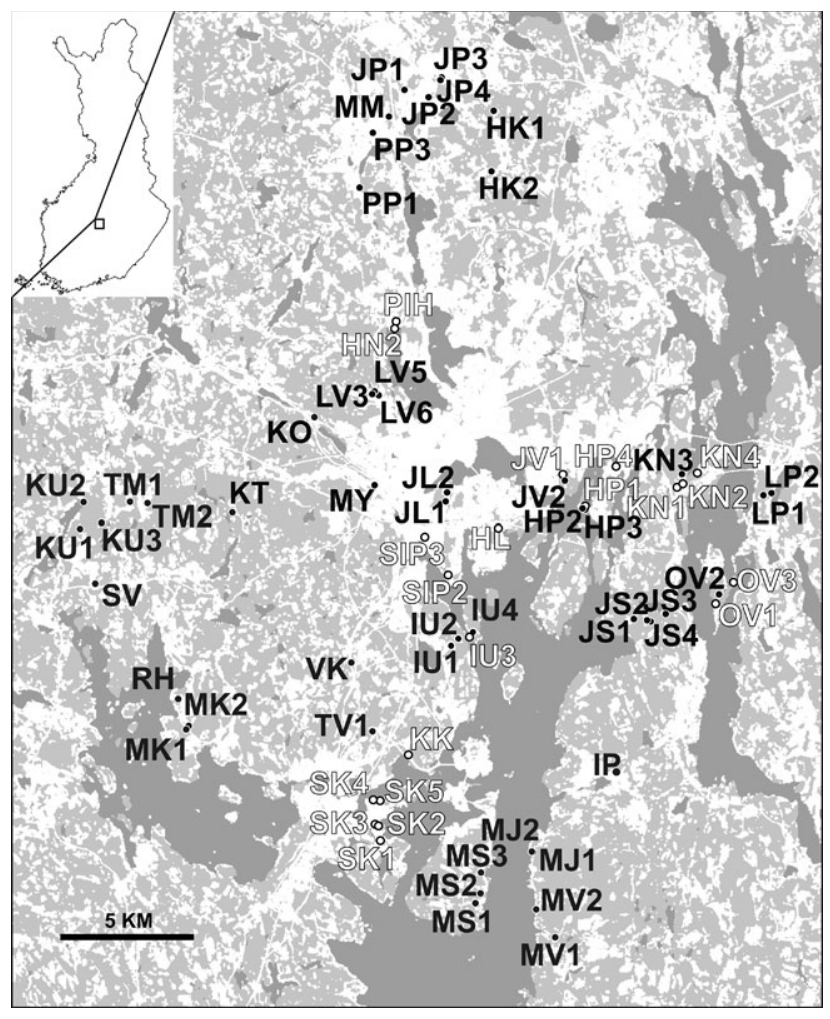

Fig. 1. Map showing the sites where Naryciinae larvae were collected. White patches: at least $30 \%$ of the adult moths that emerged belonged to parthenogenetic species. Dark grey water, light grey - forest, white - other types of land use.

Identification of host species was attempted, using DNA analysis, for all those larval remains for which the parasitoids were analysed molecularly (see below). Unfortunately, remains of the larval host were absent in many cases or we were unable to extract the DNA due to degradation or limited amounts of DNA. While emerging moths were not all identified, they were all divided into sexuals and asexuals based on reproductive behaviour; parthenogenetic females immediately lay eggs inside the larval case upon emergence. Only cases from the larger parthenogenetic Dahlica triquetrella could be reliably identified, but those were rare (41 individuals). Molecular identification by comparison of partial sequences of the COII gene with those in a previously-established reference database (Grapputo et al., 2005, sequences available in Genbank) revealed that there were five sexual species in the study area (Elzinga et al., 2011): Siederia rupicollella, S. listerella, Dahlica lazuri, D. charlottae and $D$. lichenella. All parthenogenetic moths for which DNA was examined (except $D$. triquetrella) were $D$. fennicella. However, the taxonomic status and the names are not yet certain for all the host species (see, e.g., Palmqvist, 2008; Elzinga et al., 2011). Dahlica lichenella in Finland, for example, is a parthenogenetic species (Suomalainen, 1980; Suomalainen et al., 1981; Grapputo et al., 2005; Palmqvist, 2008), whereas the D. lichenella collected in this study were sexual. Dahlica lazuri was identified by Peter Hättenschwiller as D. fumosella, which supports the hypothesis that they are the same species (Palmqvist, 2008). Similarly, S. listerella could be S. pineti (Palmqvist, 2008). In this paper, we follow the species names that were used for the reference samples in Grapputo et al. (2005).

\section{DNA extraction and sequencing}

Barcoding (Hajibabaei et al., 2007) is a molecular tool widely used to identify species and to detect the existence of cryptic 
species (Kankare et al., 2005; Smith et al., 2006, 2007; Bernardo et al., 2008; Desneux et al., 2009). The 5 ' half of the mitochondrial cytochrome c oxidase I (COI) gene is usually used in barcoding because it is very variable, generally applicable and its primers are universal (Hebert et al., 2003). Depending on the organisms investigated, a divergence of $1 \%$ to $3 \%$ among sequences is considered the threshold for considering a specimen to belong to a certain species (Kankare et al., 2005; Smith et al., 2007). In this study the barcoding protocol was applied as an additional identification tool and to determine whether there were any cryptic species among the morphologically identified parasitoids. The sequence of the barcoding fragment of the COI gene was obtained for, on average, 10 random specimens (male and female) of each morphological parasitoid species collected from different sites and, where possible, from sexual and parthenogenetic host sites. Additional samples were analysed when the two methods of identification did not give similar results.

Since mitochondrial DNA is inherited maternally in most insects, the analysis of an additional variable nuclear gene becomes essential to identify the presence of hybrid species and may account for the differences between morphological and barcoding identification (Smith et al., 2007). Although several other regions are very variable and used in phylogenetic analyses of Hymenoptera (e.g., ITS2: Wagener et al., 2006; ArgK: Ramirez et al., 2010), available primers resulted in either multiple or null amplifications for our parasitoid samples (pers. obs. JAE \& AG). Therefore, we decided to test the suitability of the Wingless gene (Brower \& DeSalle, 1998). The Wingless gene is variable enough in other insects for it to be used in lowlevel phylogenetic studies (Mitter et al., 2011) and has a rate of evolution similar to mtDNA (Brower \& DeSalle, 1998).

DNA was extracted from one hind leg of each parasitoid, which meant the specimen could be used for morphological analyses and it reduced the chances of inadvertently amplifying the DNA of parasitoid-associated Wolbachia (Linares et al., 2009). DNA was extracted using the DNeasy Blood \& Tissue Kit (QIAGEN) according to the manufacturer's protocol and resuspended in $100 \mu \mathrm{l}$ of $\mathrm{AE}$ buffer. Amplification of a fragment of about $700 \mathrm{bp}$ of the Cytochrome Oxidase I was obtained using the universal forward primer LCO and the reverse primer HCO (Folmer et al., 1993). Amplification of a fragment of about $500 \mathrm{bp}$ of the Wingless gene was carried out using the forward primer LepWG1 and the reverse primer LepWg2 (Brower \& DeSalle, 1998).

Host DNA was extracted from the remains of the host larva as described above. Amplification of a fragment of about $400 \mathrm{bp}$ of COII was obtained using a specifically-designed forward primer for Naryciinae (COII-M1-F: TTGGATTTAAACCCCATYTA) and the universal reverse primer C2-N-3389 (Simon et al., 1994). Cytochrome Oxidase II (COII) rather than COI was used, first because the specific primer COII-M1-F prevented the amplification of the parasitoid DNA and secondly because only reference sequences of COII were available for Naryciinae (Grapputo et al., 2005; Elzinga et al., 2011).

All primers were tailed with M13 primers. Amplifications were done in a C1000 Thermo Cycler (Bio-Rad) with the use of $1 \times$ Premix B (Epicentre), 10 pmol of each primer, 1.25 Units (1 Unit for the COII amplification) of Failsafe enzyme mix (Epicentre) and $2 \mu 1$ of genomic DNA, with a total volume of $20 \mu 1$. The PCR program was: $95^{\circ} \mathrm{C}$ for $3 \mathrm{~min}$, then 30 cycles of $95^{\circ} \mathrm{C}$ for $30 \mathrm{~s}$, annealing at $55^{\circ} \mathrm{C}\left(50^{\circ} \mathrm{C}\right.$ for the COII) for $30 \mathrm{~s}$ and $72^{\circ} \mathrm{C}$ for $1.5 \mathrm{~min}$, followed by a final extension at $72^{\circ} \mathrm{C}$ for 5 min. Amplification of Wingless and COII were done in two rounds of PCR of 40 cycles, using $1 \mu 1$ of the product of the first round for the second round. All $20 \mu 1$ of the PCR product was run on a $1 \%$ agarose gel. The band of the target size was cut and centrifuged through a $300 \mu$ Finntip Filter (Thermo Labsystems) at 6,000 rpm $15 \mathrm{~min}$ for each sample.

Sequencing reactions were performed using the BigDye ${ }^{\circledR}$ Terminator v3.1, Cycle Sequencing Kit (Applied Biosystems) using the M13 primers and run on an ABI 3130XL automated sequencer. All the sequences were checked for mismatches between strands and corrected in Seqscape 2.6 (Applied Biosystems). Some samples of one parasitoid species (Macrus parvulus) showed a mixture of amplification products for the COI gene suggesting the presence of pseudogenes (see Song et al., 2008). In these cases, the amplification product was cloned using the CloneJet PCR Cloning Kit (Fermentas) and NovaBlue Single Competent Cells (Novagen). Only the resulting sequences that did not contain one extra base pair and multiple stop codons were included in analyses.

\section{Analyses}

\section{Ecological parameters}

Percentage parasitism was calculated using only those host larvae from which a moth or parasitoid emerged (excluding the rare $D$. triquetrella of which only a $35 \%$ emerged). Idiobiont parasitoids may attack larvae that are already parasitized by koinobionts, killing those (Elzinga et al., 2007). Therefore, to avoid underestimating the percentage parasitism by koinobiont parasitoids, it was calculated excluding larvae from which idiobionts emerged (assuming the idiobionts neither avoid nor prefer previously parasitized hosts). Time to emergence was calculated from the day of host larval collection to the day of adult emergence. For most parasitoids development was longer when the host larva was stored for some time at $5^{\circ} \mathrm{C}$ and thus we only used the data for individuals that were kept at normal rearing temperatures (see above). Time to emergence was affected by the date on which the host larva was collected, variation in handling time, differences in developmental stage, or because development of the parasitoid was dependent on it experiencing some light or temperature threshold. Therefore, we compared times to emergence between sexes using the residuals of an ANOVA for week collected. All comparisons between sexes were made using t-tests.

\section{Parasitoid and host DNA}

Sequences for each gene were aligned with ClustalW in MEGA 4.0 (Tamura et al., 2007). A collection of reference sequences for the Naryciinae COII, available in Genbank (Grapputo et al., 2005), was added to the COII dataset for the species identification of the larval host remains. Identification was based on the clustering of the sequences with the references sequences.

To our parasitoid DNA data set we added reference sequences from related species for comparison: Diadegma semiclausum (Ichneumonidae: Campopleginae) (Genbank EU871947.1) for $\mathrm{COI}$ and Hyposoter fugitivus (Ichneumonidae: Campopleginae) (GenBank DQ538624.1) for Wingless; and for both genes, Hemichneumon subdolus (Ichneumonidae: Ichneumoninae) obtained locally and from Switzerland. Hemichneumon subdolus attacks other Psychidae species (e.g., Taleporiinae: Taleporia tubulosa and Psychinae: Psyche sp., pers. obs.) and belongs to the same tribe (Phaeogenini) as Trachyarus sp. Each parasitoid COI sequenced was queried on the BOLD database ( http://www. boldsystems.org, last accessed 10.iii.2011).

A COI phylogenetic tree was obtained using the neighbourjoining method and the $\mathrm{K} 2 \mathrm{P}$ model for nucleotide substitution with pairwise deletion according to the barcoding protocol (Ratnasingham \& Hebert, 2007). The best model of nucleotide substitution for Wingless $(\mathrm{K} 2 \mathrm{P}+\mathrm{G})$ was obtained with jModelTest 


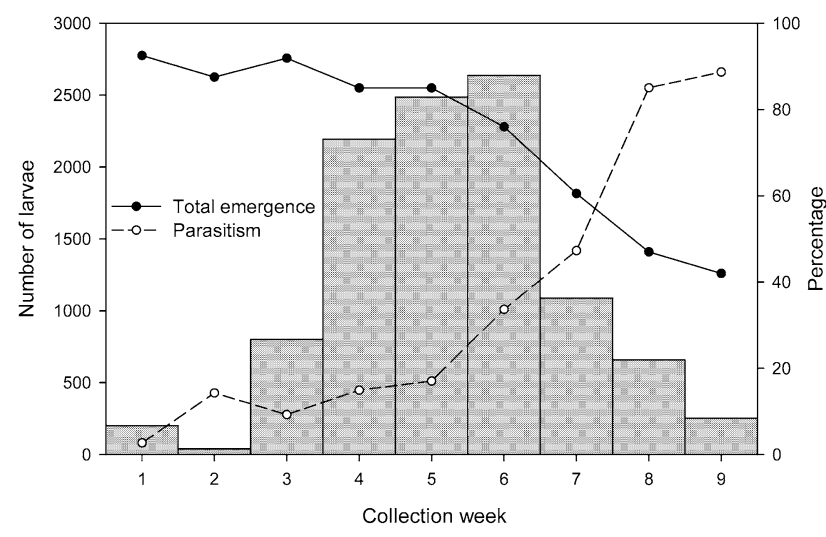

Fig. 2. Number of Naryciinae larvae collected in Central Finland, percentage emergence (adult moth or parasitoid) and overall percentage parasitism of the larvae collected each week (week 1 started March 15, 2008).

(Posada, 2008) using the Akaike Information Criterion (Akaike, 1974). Accordingly, a Wingless phylogenetic tree was obtained using the Bayesian method implemented in MrBayes (Ronquist \& Huelsenbeck, 2003) and the K2P model of substitution with rates $=$ gamma. Four MCMC chains (three hot and one cold) were run for two million generations with trees sampled every 100 generations. The first 500,000 generations $(5,000$ trees) were discarded ("burn-in" period) and the posterior probabilities were estimated for the remaining generations. Two independent Bayesian runs initiated from random starting trees were performed to check that the chains had reached stationarity.

To investigate the intra- and inter-distance distributions among parasitoid species with COI and Wingless, and compare the two genes, we used SpeciesIdentifier ver 1.7.7-dev3 (Meier et al., 2006).

\section{RESULTS}

\section{Percentage parasitism}

A total of 10,357 fully-grown Naryciinae larvae (excluding $41 \mathrm{D}$. triquetrella) were collected from the 70 sites sampled (Fig. 1). The majority of larvae were collected in weeks 15, 16 and 17 (Fig. 2). At most sites only sexual moths were collected but at about 20 sites at least $30 \%$ of the adult moths were parthenogenetic females (Fig. 1). A moth or a parasitoid emerged from $77.5 \%$ of the larvae collected. The total percentage parasitism was $25.7 \%$ (2060 parasitoids in total) of which more than $99 \%$ were identified morphologically to species level. Percentage parasitism strongly increased over time from less than $20 \%$ in the first five weeks to over $80 \%$ in the last week (Fig. 2). Successful emergence, however, decreased over time from more than $90 \%$ in the first week to less than $50 \%$ in the last week (Fig. 2), probably due to greater activity of small predators (e.g. spiders, ants and shield bugs, pers. obs. JAE). The fraction of parasitism by both koinobiont and idiobiont parasitoids increased over time, although there were clear differences between the parasitoid species (Fig. 4). Three clear cases of (pseudo-)hyperparasitism by an idiobiont were recorded (see below).

\section{Species complex}

Based on morphological characters, nine species of larval parasitoids (eight ichneumonids, one braconid) were identified (Table 1), of which one was only recently described (Zwakhals \& Elzinga, 2009). The majority of the parasitoids were koinobionts (73\%), but the composition of the parasitoid complex depended strongly upon the week in which larvae were collected (Fig. 3).

Not only did the type of parasitoid (koinobiont endoparasitoid or idiobiont ectoparasitoid) vary, there was also a large variation in other ecological characteristics. Some ecto- and endoparasitoids attack host larvae in spring, leading to higher percentage parasitism at the end of the sampling period, whereas other koinobionts attacked the host the previous year, leading to the percentage parasitism peaking earlier in the collection period (Fig. 4). Times to emergence also differed markedly among species (Fig. 6A). Some species emerged while mature host larvae were still active in the field, whereas other species of parasitoid emerged later and one species emerged only

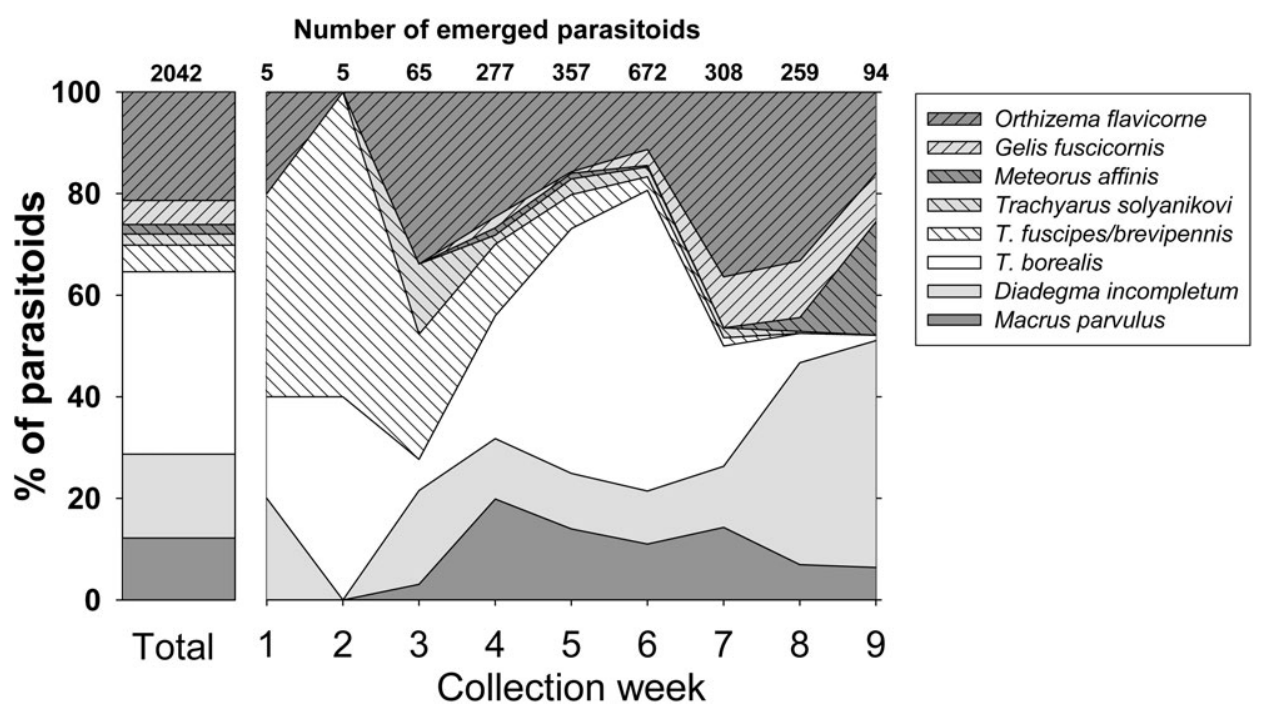

Fig. 3. Changes in the complex of parasitoid species parasitizing Naryciinae larvae in Central Finland during the period of the study, which started March 15, 2008. 


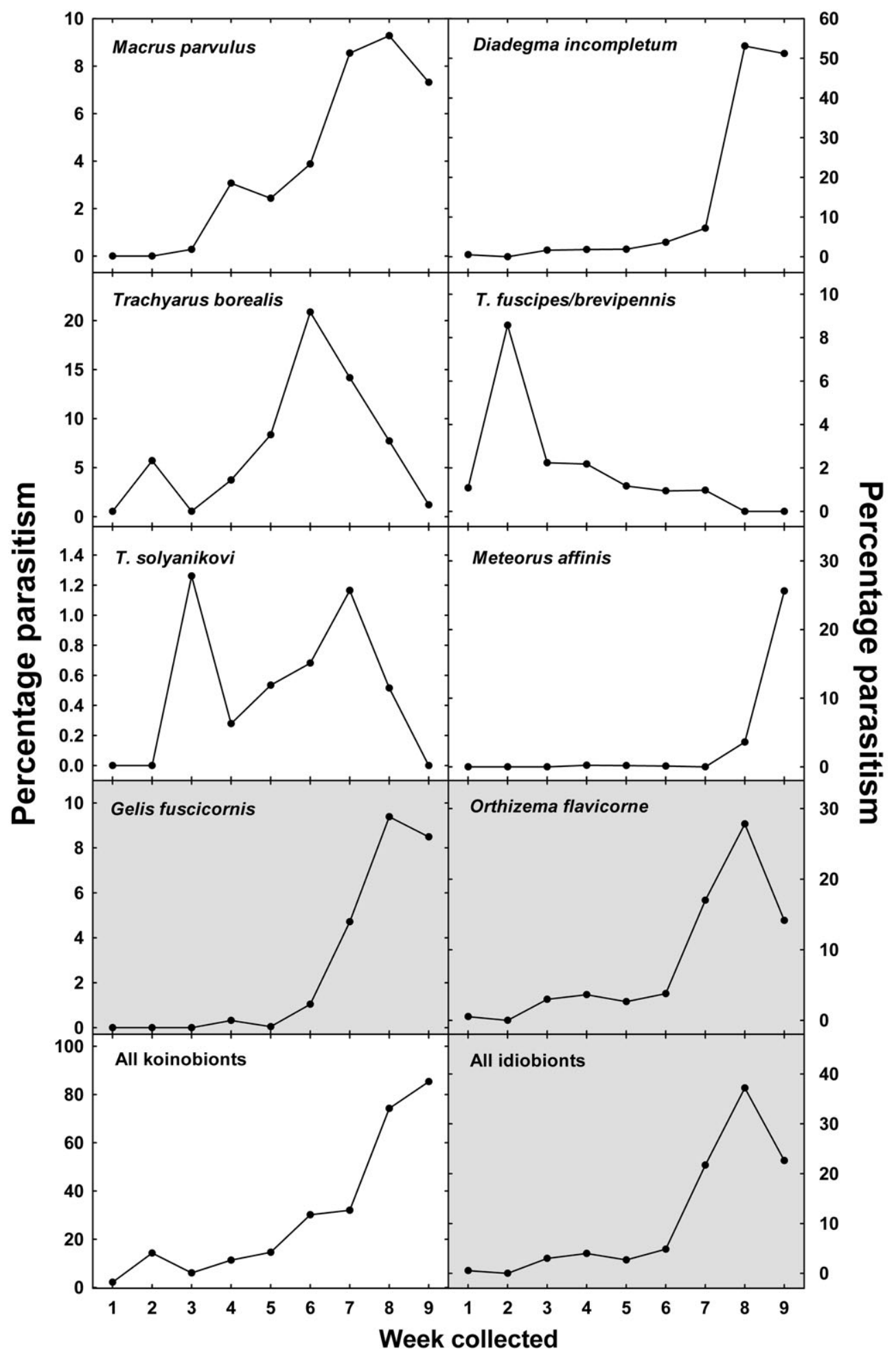

Fig. 4. Percentage parasitism of the Naryciinae larvae that were collected each week (week 1 started March 15, 2008) by each parasitoid species in Central Finland. Shaded graphs indicate percentage parasitism by idiobionts.

in autumn. The biology of each species of parasitoid is discussed in more detail below.

\section{DNA analyses}

Sequences of a fragment of $657 \mathrm{bp}$ of the COI gene were obtained for 151 individuals. The aligned sequences contained 287 variable sites (284 parsimoniously informative). None of the COI sequences matched a sequence for parasitoid species in the BOLD database (www. boldsystems.org, last accessed 10.iii.2011), but all clustered with members of their corresponding subfamily.

A fragment of 439-454 bp of the Wingless gene was obtained for 65 samples. Sequences of $M$. parvulus and D. incompletum contained insertions of 6 and $15 \mathrm{bp}$, respectively. The 65 obtained sequences contained 157 variable and parsimoniously informative sites. 
TABLE 1. Overview of the morphologically distinguished parasitoid species of Naryciinae (Lepidoptera: Psychidae) recorded in Central Finland in 2008 and the number of hosts identified. Hosts were identified by means of a mtDNA analysis (Grapputto et al., 2005).

\begin{tabular}{|c|c|c|c|c|c|c|c|c|c|c|}
\hline \multicolumn{4}{|c|}{ Parasitoids } & \multicolumn{7}{|c|}{ Identified hosts } \\
\hline \multirow[b]{2}{*}{ Family } & \multirow[b]{2}{*}{ Subfamily } & \multirow[b]{2}{*}{ Species } & \multirow[b]{2}{*}{$\begin{array}{l}\text { Number of } \\
\text { individuals }\end{array}$} & \multicolumn{6}{|c|}{ Naryciinae } & \multirow{2}{*}{ 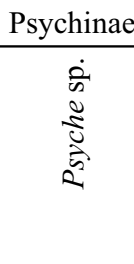 } \\
\hline & & & & 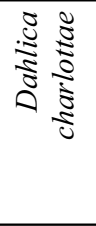 & 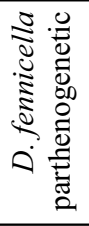 & 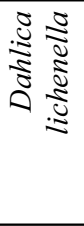 & 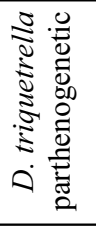 & 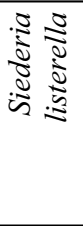 & 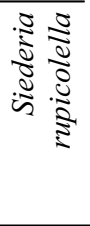 & \\
\hline Braconidae & Meteorinae & Meteorus affinis & 38 & & 2 & 3 & & 3 & & \\
\hline \multirow[t]{9}{*}{ Ichneumonidae } & Campopleginae & Diadegma incompletum & 337 & & & & 1 & 3 & & $1^{3}$ \\
\hline & & Macrus parvulus & 249 & & 5 & & & 8 & & \\
\hline & Cryptinae & Gelis fuscicornis & 97 & 2 & & & $1^{3}$ & 7 & & \\
\hline & & Orthizema flavicorne & 427 & & & 3 & & 4 & 1 & \\
\hline & Ichneumoninae & Trachyarus borealis & 733 & & & & & 13 & & \\
\hline & & Trachyarus brevipennis ${ }^{1}$ & 17 & 9 & & & & & & \\
\hline & & Trachyarus fuscipes $^{1}$ & 90 & 4 & 2 & & & 2 & 1 & \\
\hline & & Trachyarus solyanikovi & 45 & 5 & & 2 & & 3 & 1 & \\
\hline & & Trachyarus 'mix'” & 5 & & & & & & & \\
\hline
\end{tabular}

${ }^{1}$ morphological identification did not fully correspond with mtDNA identification, see Results section; ${ }^{2}$ mix of $T$. borealis and $T$. fuscipes morphological characteristics; ${ }^{3}$ morphological host identification.

The results of the DNA analyses largely correspond with the results of the morphological identification (Figs 7 and 8$)$. Of the 11 morphological groups (10 identified species, 1 unidentified species) for which more than one COI sequence was available, SpeciesIdentifier found nine clusters using a distance threshold of 3\% (Fig. 7). In all clusters, sequences from a single species were grouped together except for three clusters (1, 3 and 4) formed by 2-3 different Trachyarus species with a maximum pairwise distance of $3.34,1.06$ and $0.45 \%$, respectively (Fig. 7). T. brevipennis and T. fuscipes both formed two clusters (Fig. 7) due to large intraspecific COI variation (Table 2). For M. parvulus two subgroups can be distinguished for individuals associated with either the sexual or asexual moths or populations (Fig. 7), but the intergroup distance was lower than $3 \%$.

The phylogenetic analysis of the nuclear DNA did not always correspond to the results of the mtDNA, especially in the Trachyarus species complex (Fig. 8). Several of the specimens of species that were placed in separate clusters (e.g., T. fuscipes, T. brevipennis) in the COI analysis (Fig. 7) were grouped together in the Wingless gene analysis (Fig. 8). Moreover, several specimens that were in one COI cluster (e.g., T. fuscipes cluster 1 and 4, $T$. brevipennis and $T$. borealis cluster 3 ) were separated by the Wingless analysis. SpeciesIdentifier produced six clusters for the Wingless gene, one of which contained all five Trachyarus species and $H$. subdolus, while the other five corresponded to the COI clusters (Fig. 8). The frequency distribution of intra- and interspecific pairwise distances with COI and Wingless (Table 2, Figs 7 and 8) clearly indicate a lower variability of the Wingless gene, as well as an overlap between intra- and interspecific distances in both genes.
The results of the parasitoid DNA analyses are discussed in more detail by species or group below. All parasitoid sequences are available in Genbank (accession nos. HM020512-HM020672).

\section{Host identification}

The sequences of a fragment of $298 \mathrm{bp}$ of the COII corresponding to the positions 275 to 572 in Grapputo et al. (2005) were obtained for the remains of moth larvae. Of the 125 larval remains, we were able to extract and successfully sequence DNA from $69 \%(n=86)$. All sequences clearly clustered with a reference sequence (0-2 bp difference with a reference sequence) and could be assigned to a host species. Six of the seven Naryciinae species recorded in the study area (Elzinga et al., 2011) were detected in the larval remains (Table 1); only the rare $D$. lazuri was absent.

\section{Detailed description of species parasitizing Naryciinae}

Koinobiont endoparasitoids

\section{Diadegma incompletum (Horstmann, 1973)}

With a percentage parasitism of $5.3 \%, D$. incompletum accounted for $16.7 \%$ of all the parasitoids (Fig. 3). The percentage parasitism by $D$. incompletum remained relatively stable over the collection period but increased markedly in the last two weeks (Fig. 4). This indicates that in the wild the early-emerging females might attack late mature bagworm moth larvae since the parasitoids emerge early enough to occur while these larvae are still active in the field (Fig. 5). However, it is also possible that the development of parasitized larvae is slower than that of healthy bagworm moth larvae and thus they were caught later by the tape. 


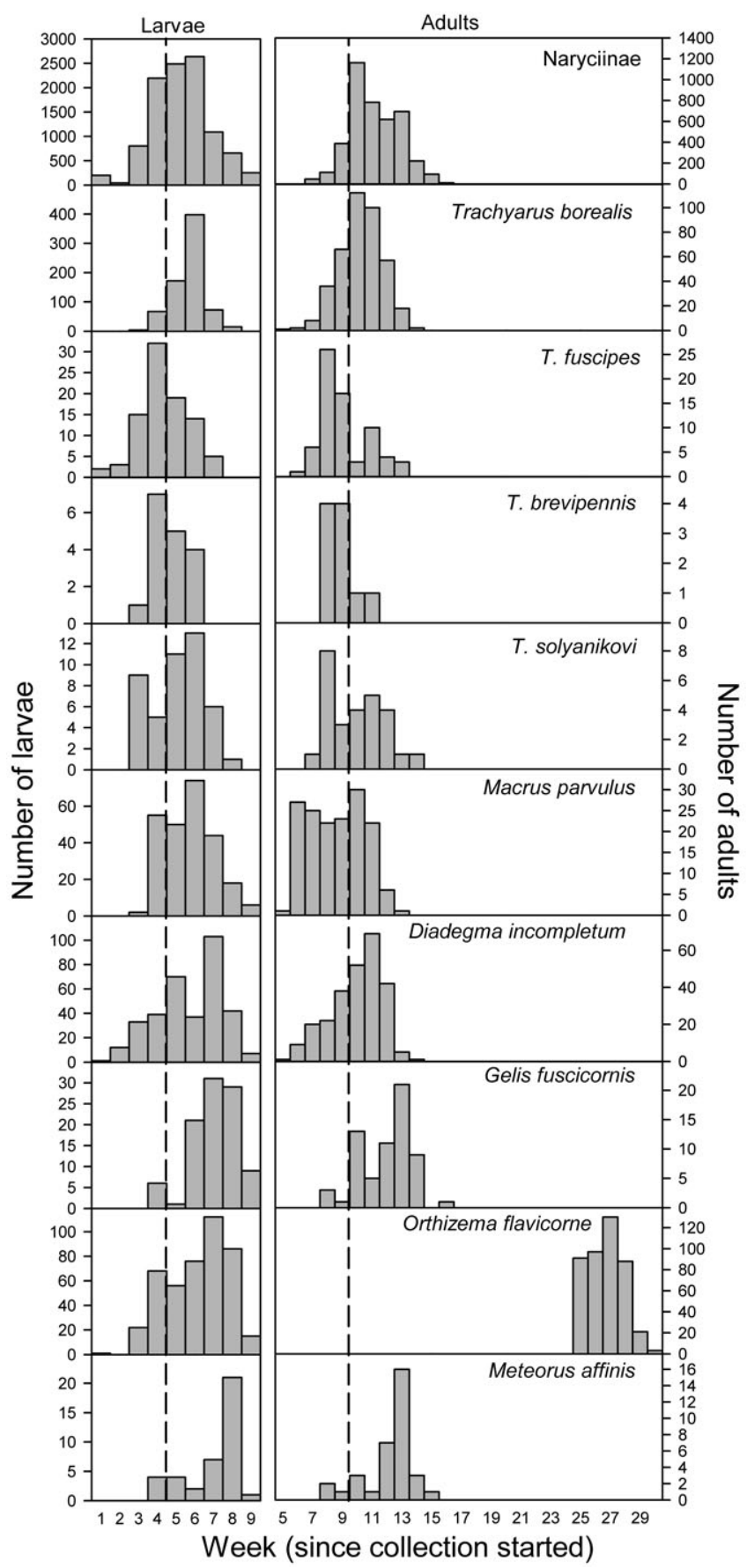

Fig. 5. Overview of the weeks when parasitized larvae of Naryciinae were collected (left) and when the adult parasitoids emerged from larvae kept under laboratory conditions (right) for each morphological species of parasitoid. The top panels show the number of Naryciinae larvae collected in each of the weeks (left) and the number of adults that emerged each week (right). The latter was shifted to four weeks later to indicate the time that host larvae emerge from eggs. The period of five weeks when some parasitoid adults emerged while mature host larvae were still active in the field is indicated by the broken lines.

The sex ratio was slightly male biased with $57 \%$ males (Chi-square test, $\mathrm{P}=0.01)$. Males were found, on average, 0.5 weeks earlier (Fig. 6B) and developed on average 4.1 days faster than females (Fig. 6A).
All hosts remains were identified as $S$. listerella (Table 1). Several $D$. incompletum emerged before winter from immature Naryciinae larvae collected in June and July. We also reared it once from a $D$. triquetrella and once from a Psyche sp. (fully grown larva, collected in July). Previous recorded hosts include Solenobia pineti, D. lichenella (both Naryciinae) and Proutia betulina (Psychinae) (Horstmann, 1973; pers. comm. Mark Shaw).

The divergence in DNA sequences within this species was very small, reaching a maximum of $0.3 \%$ in COI and $0.22 \%$ in Wingless (Figs 7 and 8 ). There were no indications that cryptic species were present.

\section{Macrus parvulus (Gravenhorst, 1829)}

The percentage parasitism by $M$. parvulus was $4.0 \%$ and accounted for $12.0 \%$ of the parasitoid complex (Fig. 3 ). The percentage parasitism increased slowly over the collection period indicating a mode of attack similar to that described for D. incompletum (Fig. 5).

Sex ratio was not significantly biased, with $54 \%$ males. Males were collected slightly earlier than females (Fig. $6 \mathrm{~B})$, but the difference was not significant $(\mathrm{P}=0.06)$. On average males developed faster than females (Fig. 6A).

Macrus parvulus was recorded from D. fennicella and S. listerella (Table 1). Previous recorded hosts include the Naryciinae D. reliqua, D. lichenella, D. inconspicuella, D. triquetrella, D. fumosella, S. alpicolella and Postsolenobia thomanni; other psychid subfamilies: Proutia betulina (Psychinae) and Taleporia tubulosa (Taleporiinae) and other unidentified; the Tortricidae Grapholita molesta, Epinotia margarotana and Hedya nubiferana; and the Nymphalidae Eurodryas aurinia, although the last seems unlikely (Horstmann, 1970; Yu et al., 2005; pers. comm. Mark Shaw). Macrus parvulus also occurs in North America (treated as a separate subspecies $M$. parvulus solenobiae) and is known to use Siederia walshella as a host (Barron \& Bisdee, 1977).

The analysis of the COI sequences shows that there are two sub-clusters in M. parvulus (Fig. 7). The average nucleotide divergence in COI between the two was $1.01 \%$ (6.4 bp). Interestingly, one sub-cluster was associated with parthenogenetic moth sites (and species) and the other with sexual moth sites (and species) (Fig. 7), suggesting the presence of cryptic species or races associated with host specialization. In contrast, these groups were not revealed when the Wingless gene was used (maximum divergence $0.44 \%$ ) (Fig. 8).

\section{Trachyarus sp.}

We morphologically identified four species of Trachyarus: T. borealis, T. solyanikovi, T. fuscipes and T. brevipennis. Five individuals could not be identified as they contained a mix of the morphological characters of $T$. borealis and T. fuscipes.

All these Trachyarus species are larval-pupal parasitoids and emerged from pupae of the host (with the exception of 7 individuals, representing all 4 morphological species, that emerged from host larvae at a prepupal stage). No differences in times to emergence were found between the four species (Fig. 6A). However, there 


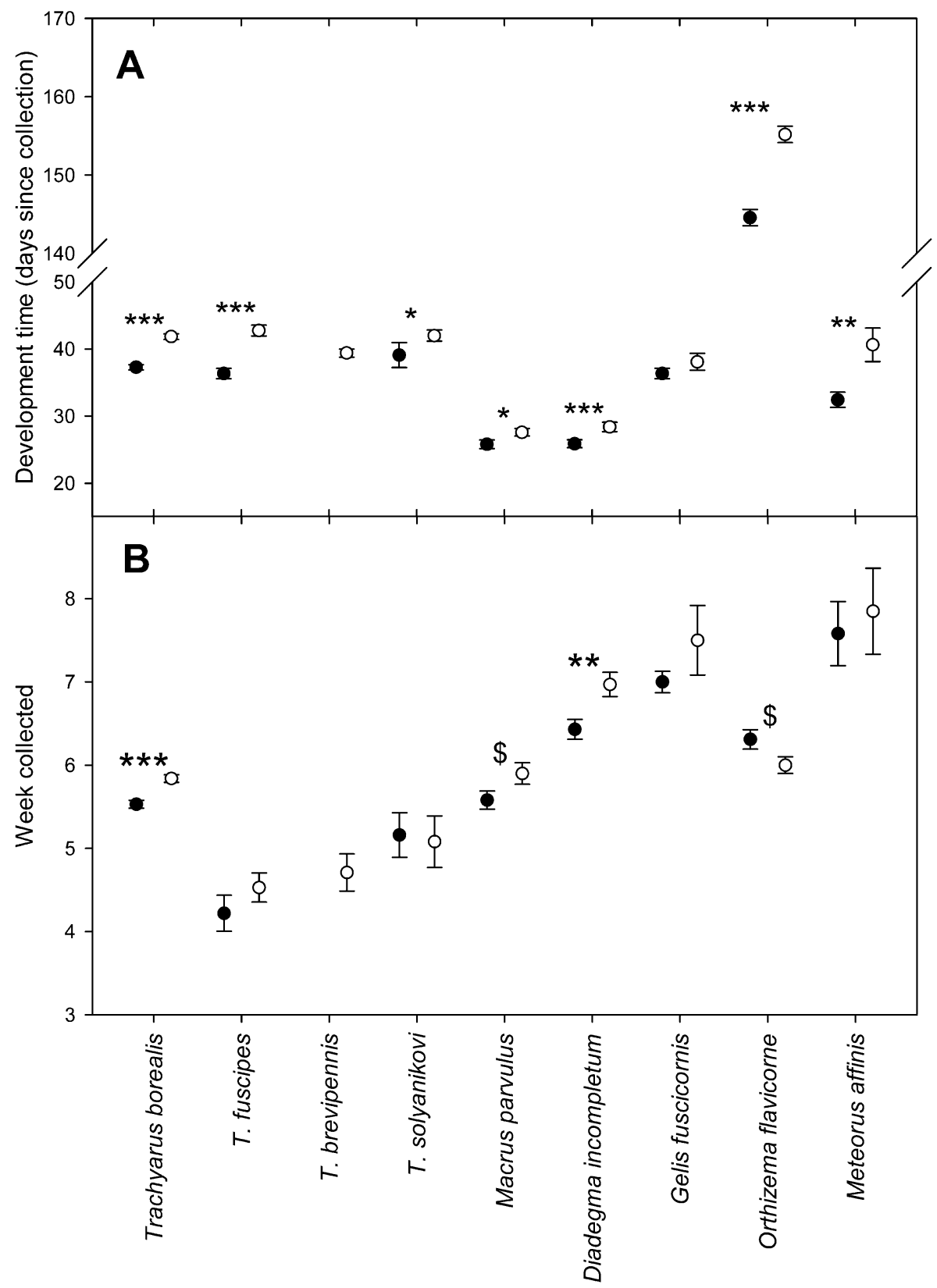

Fig. 6. A - times to emergence (from date of collection of the parasitized host to adult emergence, \pm s.e.), and B - week collected ( \pm s.e.) for the males and females of morphological species of parasitoids that emerged from the Naryciinae hosts. Stars indicate significant differences between males and females (t-tests, of residuals for week of collection).

were differences between species in the average week the host larvae were collected (Fig. 6B, ANOVA corrected for sex, $\mathrm{P}<0.001)$. Trachyarus fuscipes was found earliest, followed by $T$. solyanikovi and T. borealis (post-hoc tests, $\mathrm{P}<0.05)$. T. brevipennis did not differ significantly in collection time from the other species, perhaps due to small sample size.

The molecular identification did not correspond fully with the morphological identification (Figs 7 and 8). Sequences of COI differed between species and there was also great variation within morphological species (Table 2, Fig. 7). Intra-species sequence divergence was greater than $1 \%$, especially within $T$. fuscipes and T. brevipennis (Table 2, Fig. 7). On the other hand, some morphologically different species had similar or identical COI sequences, such as several specimens identified as either T. fuscipes, T. brevipennis or T. solyanikovi (Table 2, Fig. 7). The Wingless gene varied less between the different groups (Table 2, Fig. 8) and SpeciesIdentifier clustered all of them together, including the $H$. subdolus sequences. In the phylogenetic analyses several specimens clustered in different groups in the COI and Wingless analyses (Figs 7 and 8). We discuss the observed patterns in more detail for each morphological species below.

Interestingly, the DNA data suggests that $H$. subdolus is not less related to the various Trachyarus species than the Trachyarus are among themselves (Figs 7 and 8). This could indicate that $H$. subdolus should not be placed in a separate genus. 


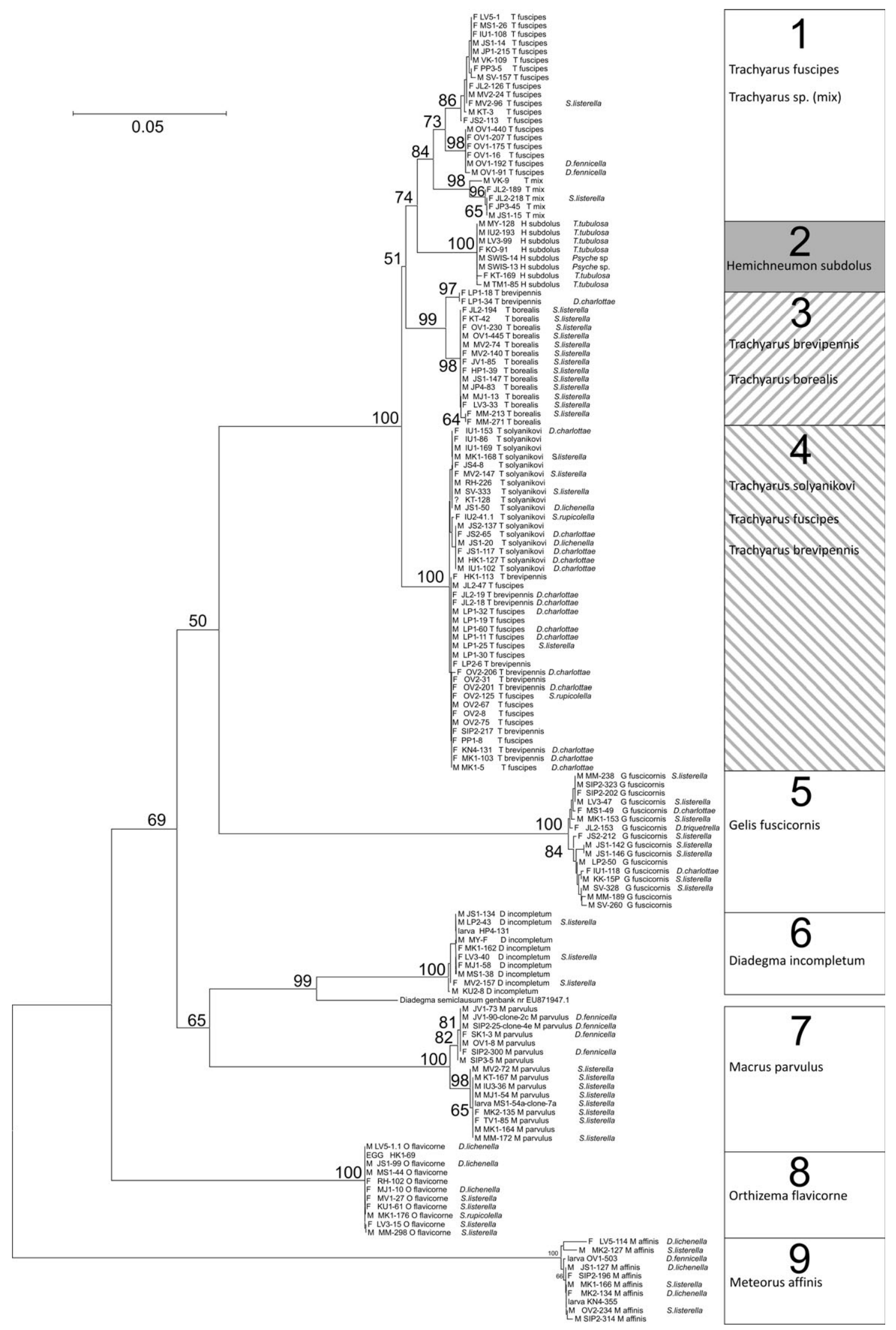

Fig. 7. Phylogenetic tree (neighbour-joining, K2P model, pairwise deletion) based on COI sequences (657 bp) of the parasitoids that emerged from Naryciinae in Central Finland. Sequences of Hemichneumon subdolus (a parasitoid of Taleporia and Psyche sp., Psychidae) from Central Finland and Switzerland (SWIS) and a reference sequence of Diadegma semiclausum (Genbank EU871947.1) were added to the analyses for comparison. For each sample, gender ( $\mathrm{F}$ - female, $\mathrm{M}$ - male), the individual code (the first part indicates the sample site, see Fig. 1), the morphological species and, where available, host species, are indicated, respectively. Bootstrap values higher than 60 are shown at the nodes. The scale indicates $\%$ bp differences. Blocks with numbers indicate the different clusters obtained using SpeciesIdentifier and the morphological species they contain. 


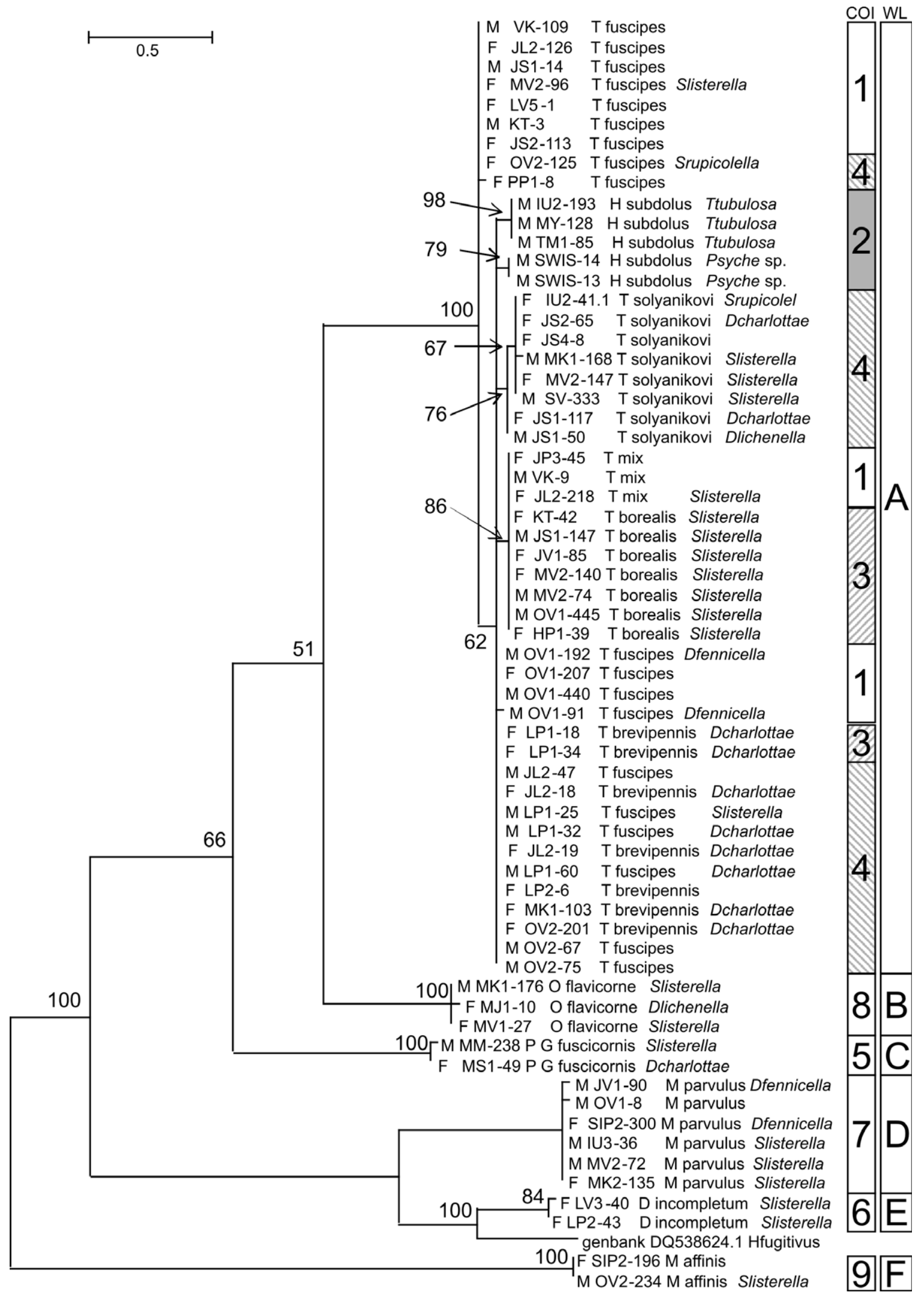

Fig. 8. Phylogenetic tree (Bayesian method, $\mathrm{K} 2 \mathrm{P}+\mathrm{G}$ model) based on Wingless sequences (441-464 bp) of the parasitoids that emerged from Naryciinae in Central Finland. Sequences of Hemichneumon subdolus (a parasitoid of Taleporia and Psyche sp., Psychidae) from Central Finland and Switzerland (SWIS) and a reference sequence of Hyposoter fugitivus (Genbank DQ538624.1) were added to the analyses for comparison. For each sample, gender ( $\mathrm{F}$ - female, $\mathrm{M}$ - male), the individual code (the first part indicates the sample site, see Fig. 1), the morphological species and, where available, host species, are indicated, respectively. Bayesian posterior probabilities are shown at the nodes. The scale indicates \% bp differences. Bars indicate the different clusters obtained using SpeciesIdentifier for the COI (1-9, see Fig. 7) and the Wingless (A-F) gene. 
TABLE 2. Genetic distance (p-model, pairwise deletion) for COI and Wingless (shown in italics) sequences within and between morphological species of the Trachyarus sp. complex belonging to different mtDNA (COI) clusters, as shown in Fig. 7.

\begin{tabular}{|c|c|c|c|c|c|c|c|c|c|c|c|c|c|c|}
\hline \multirow[t]{2}{*}{ Group } & \multirow[t]{2}{*}{ Morphological species } & \multirow[t]{2}{*}{$\begin{array}{c}\text { Cluster } \\
(\mathrm{COI})\end{array}$} & \multicolumn{2}{|c|}{$\begin{array}{l}\text { Number of } \\
\text { sequenced } \\
\text { individuals }\end{array}$} & \multicolumn{2}{|c|}{$\begin{array}{l}\text { Maximum sequence } \\
\text { divergence within } \\
\text { group }(\%)\end{array}$} & \multicolumn{8}{|c|}{$\begin{array}{l}\text { Average pairwise divergence between groups } \\
\qquad(\%)\end{array}$} \\
\hline & & & $\mathrm{COI}$ & Wingless & $\mathrm{COI}$ & Wingless & 1 & 2 & 3 & 4 & 5 & 6 & 7 & 8 \\
\hline 1 & Trachyarus fuscipes & 1 & 19 & 10 & 1.52 & 0.22 & & 0.5 & 0.7 & 0.5 & 0 & 0.4 & 0.5 & 0 \\
\hline 2 & $T$. sp. unidentified & 1 & 5 & 3 & 0.92 & 0 & 2.4 & & 0.6 & 0 & 0.4 & 0.9 & 0.9 & 0.4 \\
\hline 3 & Hemichneumon subdolus & 2 & 8 & 5 & 0.30 & 0.69 & 3.3 & 4.3 & & 0.6 & 0.6 & 1 & 1.1 & 0.6 \\
\hline 4 & T. borealis & 3 & 14 & 7 & 0.15 & 0 & 3.7 & 4.1 & 4.5 & & 0.5 & 0.9 & 0.9 & 0.5 \\
\hline 5 & T. brevipennis & 3 & 2 & 2 & 0.15 & 0 & 3.3 & 3.8 & 4.1 & 0.9 & & 0.4 & 0.5 & 0 \\
\hline 6 & T. solyanikovi & 4 & 17 & 8 & 0.30 & 0.47 & 3.8 & 4.3 & 4.1 & 3.4 & 3.4 & & 0.8 & 0.4 \\
\hline 7 & T. fuscipes & 4 & 13 & 9 & 0 & 0.46 & 3.8 & 4.4 & 4.0 & 3.5 & 3.5 & 0.2 & & 0.5 \\
\hline 8 & T. brevipennis & 4 & 10 & 5 & 0.15 & 0 & 3.8 & 4.3 & 4.0 & 3.5 & 3.5 & 0.2 & 0 & \\
\hline
\end{tabular}

\section{Trachyarus borealis Zwakhals, 2009}

The most common parasitoid was T. borealis, accounting for $10.9 \%$ of the parasitism and $35.6 \%$ of all parasitoids (Fig. 3). Sex ratio was unbiased (47.5\% males). There was a small but significant difference in the week of collection with males recorded on average 0.3 weeks earlier than females (Fig. 6B). On average males take four days less to complete their development than females (Fig. 6A). Percentage parasitism did not show a consistent pattern over the collection period (Fig. 4), suggesting that parasitism occurred before winter.

Interestingly, all host remains identified were $S$. listerella (Table 1). Since $T$. borealis was only recently described (Zwakhals \& Elzinga, 2009), no other host records are available.

The DNA sequences of this species vary very little (Figs 7 and 9, Table 2). The COI sequence of two T. brevipennis were only $0.9 \%$ divergent from $T$. borealis (Fig. 7, Table 2), but the Wingless sequences clustered these two specimens with the T. fuscipes/brevipennis group and their host species also differ (D. charlottae, Fig. 8). Average divergence from other Trachyarus clusters was more than 3\% with the COI sequences but less than $1 \%$ with the Wingless sequences (Table 2).

\section{Trachyarus fuscipes (Thomson, 1891)}

Trachyarus fuscipes accounted for $1.5 \%$ of all parasitism and $4.6 \%$ of all parasitoids (Fig. 3). There were no significant differences in the week of collection for males and females (Fig. 6B). Male time to emergence was, on average, 5.3 days shorter than that of females (Fig. 6A). Sex ratio was unbiased (46\% males). Percentage parasitism was highest for host larvae collected early in spring (Fig. 4), suggesting they were parasitized before winter.

The host species could not be determined in many cases, but a mix of different Naryciinae species was found: D. charlottae, D. fennicella $S$. listerella and $S$. rupicolella (Table 1). Previously recorded hosts include the Naryciinae D. triquetrella, D. nickerlii, D. charlottae, Siederia pineti, S. alpicolella, S. listerella, Eosolenobia manni and Brevantennia styriaca; and from other psychid subfamilies Anaproutia raiblensis (Psychinae), Bacotia claustrella (Psychinae) and T. tubulosa (Taleporiinae) (Diller, 1988; Yu et al., 2005; Gokhman, 2007).
The DNA results are not consistent with the morphological identification. Based on the COI data, T. fuscipes were placed in two clusters (1 and 4) separated by more than 3\% sequence divergence (Fig. 7, Table 2). There was very little variation in cluster $4(0.15 \%$ maximum divergence), with all but one sequence identical, while in cluster 1 the maximum divergence was $1.53 \%$ (Table 2 , Fig. 7) due to specimens from one parthenogenetic site (OV1). The phylogenetic analysis based on the Wingless gene also indicates two groups (Fig. 8), but, interestingly, they consist of a mixture of the two COI clusters. There are no differences in the ecological characteristics (time to emergence, collection week) of the two T. fuscipes clusters (neither for groups based on COI or Wingless). Information on host use was too limited to allow any conclusions on potential cryptic host specialization. In most cases, the sequences of $T$. brevipennis were identical with those of $T$. fuscipes (see below).

\section{Trachyarus brevipennis Roman, 1918}

A total of seventeen short-winged females were classified based on their morphology as T. brevipennis. Total percentage parasitism was $0.3 \%$ and this species made up $0.8 \%$ of all parasitoids. All identified host remains belong to D. charlottae, which also hosted T. fuscipes (Table 1). Host records reported in the literature are D. charlottae, S. listerella, S. alpicollela and Brevantennia sp. of the Naryciinae, and Psyche (=Fumea) sp., Anaproutia comitella and A. raiblensis of the Psychinae (Diller, 1988; Gokhman, 2007).

The COI sequences formed two groups (Fig. 7). Most COI sequences of the morphologically identified T. brevipennis clustered with those of T. fuscipes (cluster 4). The remainder clustered with $T$. borealis (Table 2, Fig 7). All the $T$. brevipennis Wingless sequences were identical to those of many $T$. fuscipes specimens. This suggests that T. brevipennis is not a valid species and is a synonym of T. fuscipes. This would also explain why only females were recorded. Further data supporting $T$. fuscipes and $T$. brevipennis being one species was that the average week of collection was the same (Fig. 6B). Gokhman (2007), however, mentions that $T$. brevipennis males exist, although they are not described, and also suggests that there are winged morphs of this species. 


\section{Trachyarus solyanikovi Gokhman, 2007}

Trachyarus solyanikovi accounted for $0.7 \%$ of all parasitism and $2.3 \%$ of all parasitoids (Fig. 3). The collection week for males and females did not differ significantly (Fig. 6B). Average time to emergence of males was 3.3 days shorter than that of females (Fig. 6A). Sex ratio was unbiased (44\% males).

Hosts identified to date are a mix of different Naryciinae: D. charlottae, D. lichenella, S listerella and S. rupicolella (Table 1). Previous studies mention only the Naryciinae D. charlottae, D. nickerlii, D. triquetrella and $S$. listerella as hosts (Gokhman, 2007).

The average divergence of COI sequences between $T$. solyanikovi and T. fuscipes (cluster 4 including T. brevipennis) was extremely small $(0.2 \%$ divergence corresponding to only $1.3 \mathrm{bp}$ ) (Fig. 7, Table 2). Nevertheless, a consistent mutation ( $\mathrm{C}$ in cluster 4 to $\mathrm{T}$ in $T$. solyanikovi on the $234^{\text {th }} \mathrm{bp}$ ) was present in the two groups. Similarly, the Wingless sequences were similar except for a consistent mutation (position 46, G in all other Trachyarus samples to A) (Table 2, Fig. 8).

\section{Trachyarus 'mix'}

Five individuals could not be identified morphologically as they had both $T$. borealis and $T$. fuscipes characteristics. The COI data clustered them as a sister group of the T. fuscipes cluster 1 (Fig. 7), although with an average divergence of $2.4 \%$ (Table 2 ). On the other hand, the Wingless sequence of all specimens was identical to that of T. borealis (Fig. 8).

\section{Meteorus affinis (Wesmael, 1835)}

Meteorus affinis accounted for $0.6 \%$ of the parasitism and $1.8 \%$ of all parasitoids (Fig. 3). More males than females emerged $(65 \%$, Chi-square test, $\mathrm{P}=0.07)$. Collection week was not different between the sexes (Fig. 6B). Males emerged 9.3 days earlier than females (Fig. 6A). Percentage parasitism strongly increased towards the end of the collecting period, suggesting that parasitism occurs in spring.

No indication of a specific Naryciinae host was found. Skin remains were identified as $S$. listerella, D. fennicella and D. lichenella (Table 1). Previously reported host range is quite wide in this species: $S$. alpicolella and $D$. lichenella (Naryciinae), T. tubulosa (Taleporiinae), Luffia ferchaultella and Psyche casta (Psychinae) of the Psychidae, and Archips oporana (Tortricidae) and other (micro-) Lepidoptera hiding in moss and lichen such as Infurcitinea argentimaculella (Tineidae) and Scoparia sp. (Crambidae) (Yu et al., 2005).

The DNA data did not indicate a potential cryptic species as little $(1.2 \%, \mathrm{COI})$ or no variation (Wingless) was recorded (Figs 7 and 8).

Idiobiont ectoparasitoids

\section{Orthizema flavicorne (Schmiedeknecht, 1905)}

With a percentage parasitism of $5.4 \%$, O. flavicorne accounted for $20.8 \%$ of all parasitoids found (Fig. 3). Sex ratio was not biased $(47 \%$ males, $\mathrm{n}=427)$. Females emerged from slightly earlier collected larvae than males
(Fig. 6B), which indicates that they first lay female eggs. Time to emergence was not affected by treatment (immediately placed under rearing conditions or temporarily stored in the cold). All individuals emerged in autumn (Fig. 5). On average males took 7.5 days less to complete their development than females (Fig. 6A). Since time to emergence is reduced by approximately seven days for each week the host was collected, it is clear that emergence is independent of collection week and dependent on light or temperature thresholds. The percentage parasitism by $O$. flavicorne increased toward the later period of collection (Fig. 4), suggesting that it becomes more active as temperatures increase. Five adult females were recorded on the tape in April, three of which were on a host larva. (Only one adult parasitoid emerged from these three larvae). A parasitoid egg, identified genetically, was found in April 2009 inside a case on an immobilized larva, confirming that this species oviposits in spring. The parasitoid larva exhibits an interesting behaviour: it expels the host larval remains from the case (in $>99 \%$ of all specimens). Because this species has a long development time lasting throughout the summer, this behaviour may prevent potentially detrimental effects of the decay of the host remains.

S. listerella, D. lichenella and S. rupicolella were identified as hosts (Table 1). No other host species are currently known (M. Schwarz, pers. comm.).

The DNA analysis did not indicate cryptic species were present (Figs 7 and 8) with no (COI) or just 1 variable site (Wingless).

\section{Gelis fuscicornis (Retzius, 1783)}

Gelis fuscicornis accounted for $1.2 \%$ of the parasitism and made up $4.7 \%$ of all parasitoids (Fig. 3). The sex ratio was strongly male biased $(87 \%)$. Collection week for males and females was similar (Fig. 6B). No significant differences in time to emergence between the sexes were observed (Fig. 6A). Similar to O. flavicorne, percentage parasitism strongly increased over the last weeks of collection (Fig. 4), suggesting that this parasitoid becomes more active at higher temperatures. It is known from other Gelis species that adult females overwinter (Schwarz \& Boriani, 1994; Schwarz \& Shaw, 1999). The large majority of adults emerged after active fully-grown larvae disappeared from the field (Fig. 5), suggesting that at least the next generation may use alternative host species.

Three different Naryciinae species were identified as hosts: S. listerella, D. charlottae, and D. triquetrella (Table 1). This species is reported to have a wide range of hosts, from Naryciinae (Dahlica spp. including D. lichenella) to Tortricidae, Coleophoridae and other Lepidoptera, and is also a pseudo-hyperparasitoid of a wide range of species of Hymenoptera (Schwarz \& Boriani, 1994; Schwarz \& Shaw, 1999; Yu et al., 2005). Indeed, three instances of hyperparasitism were recorded in which G. fuscicornis emerged from the remains of another parasitoid that had previously parasitized the host larva. 
No evidence of cryptic species was present in the DNA data with a variation of only $0.76 \%$ in $\mathrm{COI}$ and $0.23 \%$ in Wingless (Figs 7 and 8).

\section{DISCUSSION}

\section{Differences in the ecology of the parasitoids}

From the results it is clear that the Naryciinae in Finland are attacked by a variety of parasitoids with a wide range of life histories. The types of parasitoid range from koinobiont endoparasitoids to idiobiont ectoparasitoids. The time of emergence, time of attack and the level of host specificity also vary.

Differences in time of emergence indicate that the different species of parasitoid attack different stages of the hosts. Several of the parasitoids emerged when fullygrown larvae were still climbing the trees. The increase in percentage parasitism over the period of collection indicates that $D$. incompletum and $M$. parvulus attack fullygrown larvae in spring. However, parasitism is not exclusively directed toward fully-grown larvae and these endoparasitoids also attack immature larvae and overwinter inside them. Diadegma incompletum also emerged from immature larvae just before winter. Trachyarus species, however, seem to only attack and overwinter in immature larvae. Gelis fuscicornis and especially O. flavicorne emerge late in the season and Gelis spp. are known to overwinter as adults. Both species attack fully-grown larvae in spring, although it is likely that G. fuscicornis has at least one extra generation during the year, but the host is unknown.

It is clear that small differences in the timing of the occurrence of either immature or fully-grown larvae of sexual and parthenogenetic Naryciinae may influence their percentage parasitism. Indeed different species of Naryciinae vary in the timing of the appearance of fullygrown larvae in spring (Elzinga et al., 2011).

Furthermore, the immobilisation of larvae on the tape can create biases in the percentage parasitism recorded, as well as an increase in percentage parasitism. Variation in timing between collections may leave the hosts differentially exposed to parasitoids, which could cause variation in percentage parasitism. Some of the koinobionts, such as $M$. parvulus, D. incompletum and $M$. affinis, that attack larvae in the previous season, may also attack larvae in spring that are stuck on the tape. On the other hand, the idiobionts $G$. fuscicornis and $O$. flavicorne paralyze larvae before laying an egg and, consequently, all the parasitization recorded must have occurred after the host larvae were caught by the tape.

\section{Host specificity}

Knowledge of host use is scarce for most parasitoid species and thus levels of specialization are hard to determine without a greater knowledge of the parasitism of alternative hosts. Based on the knowledge we have gathered so far, however, several levels of specialization in the complex of parasitoids attacking Naryciinae can be distinguished: generalist (but specialist on some ecological characteristic of the hosts), specialist on
Psychidae, specialist on Naryciinae and potential specialist of a species of Naryciinae.

Two species are clearly generalists, but probably specialize on concealed hosts (such as larvae of Psychidae in their cases): G. fuscicornis and M. affinis and possibly a third species, M. parvulus (but see discussion on cryptic species). Gelis species including G. fuscicornis are known to be generalists, attacking all kinds of concealed hosts (Schwarz \& Shaw, 1999). The large male sex bias in this species indicates that the Naryciinae are not its optimal hosts. Many parasitoids lay only unfertilised male eggs in low quality hosts (Charnov \& Skinner, 1985; Godfray, 1994; King, 1987). It is therefore plausible that G. fuscicornis uses hosts other than Naryciinae during the year. The low percentage parasitism recorded for $M$. affinis combined with the scarce knowledge of its host use indicate that this species is not a specialist on Naryciinae or even Psychidae. Percentage parasitism may thus not be determined by the presence of (sexual or parthenogenetic) Naryciinae but of alternative hosts. Alternative nonpsychid hosts could include Tortricidae, which have very similar lifestyles, i.e., construct a case. Indeed one of the species, M. parvulus, is associated with tortricid hosts (but see discussion below on cryptic species).

Although reliable host records are rare, especially since hosts cannot always be determined morphologically, it seems that $D$. incompletum and $O$. flavicorne and most of the Trachyarus species are potential specialists on Psychidae. In our own limited samples of subfamilies of Psychidae other than Naryciinae, the first two species were recorded, but the Trachyarus species were only recorded from Naryciinae hosts. The problematic taxonomy of Trachyarus species (see discussion below) may have obscured any specialization on Psychidae. However, the potential for specialization on Naryciinae exists, especially for $T$. borealis. So far, we have not recorded this species from other Psychidae and the large numbers recorded in this study indicate that the Naryciinae are at least its principal host species. The limited numbers of larval remains that were analysed indicate a potential specialism on $S$. listerella, but more skin remains need to be analysed to confirm this.

Variation in the presence of alternative hosts associated with differences in habitat could potentially have caused the differences in the percentage parasitism of sexual and parthenogenetic Naryciinae (Kumpulainen et al., 2004) but no specific differences in habitat have yet been observed between sexuals and parthenogenetics (Elzinga, pers. obs.).

\section{Molecular analyses}

It is quite common among parasitoids that distinct subspecies associated with different hosts remain undetected when only morphological methods of identification are used (Kankare et al., 2005; Smith et al., 2006, 2007; Bernardo et al., 2008). Molecular analyses are a powerful tool for detecting cryptic species associated with host specialization. This study shows some evidence for cryptic speciation or race formation associated with host specialisation in one species, M. parvulus. Barcoding using the 
mitochondrial COI gene divided this species into two groups. These are associated with either parthenogenetic or sexual moth hosts. However the nuclear DNA did not support this subdivision. Nevertheless the overall variation in Wingless was consistently lower than in COI and thus two distinct clusters may not have been resolved due to the lower resolution of this gene. The separation into two groups could also reflect environmental factors rather than a specialization on sexual and parthenogenetic moths. Another possibility is that the differences in COI sequences reflect geographic variation. However, since the sites from which the sexual and parthenogenetic individuals came were geographically mixed, this is unlikely. Analyses of more variable nuclear markers and specimens with more host remains is necessary to confirm that $M$. parvulus consists of two cryptic species or races associated with different types of host.

In the Trachyarus species complex there are many species with few and often unreliable distinguishing characteristics (Gokhman, 2007), making morphological identification of specimens very difficult. Our DNA data analyses confirmed that species boundaries are indistinct in this group.

First, some of the described, morphologically distinct, species appeared to be just one species. Based on the data, T. brevipennis did not appear to be a separate species. Both the COI and Wingless sequences of T. brevipennis clustered with those of $T$. fuscipes. T. brevipennis females have reduced wings: their main distinguishing characteristic. However, many other parasitoid species show alary polymorphism (Godfray, 1994). Thus, it is likely that $T$. brevipennis is a morphotype of (a taxon now classified within) $T$. fuscipes, which would also explain why no male specimens were recorded for this species.

Second, one morphological species, T. fuscipes, formed two distinct COI clusters with greater than $3 \%$ divergence and thus could be considered as two separate species. The nDNA also divided the species into two clusters but they do not correspond to the mtDNA clusters. Incongruence between these molecular markers could be due to secondary contact and hybridization of these two species (Seehausen, 2004). The incongruence between the mtDNA and nDNA clustering, in Trachyarus groups other than $T$. fuscipes, indicates that hybridization and introgression may have occurred frequently in this species complex. If a female of one species mates with a male of another species their offspring will have the mtDNA of the mother and possibly a copy of nDNA of the father. Further hybrid matings in combination with chromosomal crossovers may lead to more complex patterns of incongruence between morphology, mtDNA and nDNA. This process may also lead to morphologically intermediate forms which can be difficult to assign to a species (such as the Trachyarus 'mix' individuals in this study) and may account for why so many species have been described for Trachyarus (Gokhman, 2007).

Incongruence between mtDNA and nDNA data is regularly found in genetic analyses of parasitoids and is often associated with incongruence between species identifica- tion and host use (Smith et al., 2006, 2007; see also Dorchin et al., 2009 for an example of phytophagous insects and host plant use). Most often the incongruence is attributed to hybridization of two species or races, which results in the offspring parasitizing both the hosts associated with the father and/or those associated with the mother (Smith et al., 2007).

Third, the data indicates that the taxonomy of Trachyarus and related genera, such as Hemichneumon, are in need of revision and that a robust analysis using molecular data is needed. It will, however, be difficult to decide the boundaries between species when there is no information on reproductive isolation. In order to determine whether they are a heterogeneous species, races or sister species ideally one needs to estimate the amount of gene flow occurring between groups (Dorchin et al., 2009; Forbes et al., 2009).

The pattern in the DNA that was recorded for the Trachyarus group is a good example of the problems that may occur in current large-scale barcoding studies using COI as a marker (Hebert et al., 2003). One important goal of large-scale barcoding is to detect the number of species in a sample. However, it is not clear how species can be reliably distinguished from each other based only on COI sequences (e.g., Rubinoff, 2006; Frézal \& Leblois, 2008). The use of a fixed genetic distance to separate species has been proposed. However, different genetic differences are used (e.g., $>3 \%,>2 \%,>1 \%$ ) all of which seem to be rather arbitrary (Rubinoff, 2006). In our dataset $T$. solyanikovi would not have been separated from T. fuscipes using any of these genetic distances. Another method is to use a percentage based on the amount of intraspecific variability (Frézal \& Leblois, 2008). Several cut-off points are proposed ranging from ten times the intraspecific variability to just two times (Meyer \& Paulay, 2005), depending on the group of species. Apart from the fact that often only a few samples of one species are available to calculate such variation, different taxonomic groups may have different rates of molecular evolution. From our data it is clear that even within closely related species, intraspecific variation is much larger in some, e.g., in $T$. fuscipes, than in others, e.g., H. subdolus, even though the latter was sampled at a much larger geographical scale. Branching patterns of young species and hybridization can be interpreted using independent genetic covariates such as nuclear markers (Smith et al., 2007). However, the use of a nuclear gene is often impeded by the lack of suitable primers or low differentiation of closely related species.

\section{CONCLUSIONS}

Several parasitoid species with a wide range of life histories attack both sexual and parthenogenetic Naryciinae. Large differences in the time and mode of attack and in the level of specialization of the parasitoids may account for the differences in the percentage parasitism of the different Naryciinae hosts. A more detailed analysis of the percentage parasitism, taking into account variation in life histories of both moths and parasitoids, is needed to 
determine whether parasitoids play a role in maintaining the coexistence of sexual and parthenogenetic species as suggested by Kumpulainen et al. (2004).

Taxonomists and ecologists will benefit from using DNA barcoding together with traditional taxonomy based on morphology. In our case it enabled us to assign unknown males to females of known species. It can be used to determine whether two species are distinct or just different morphs of the same species and which species consist of multiple clusters associated with different hosts or habitats. A good example of its usefulness is that DNA barcoding can be used to identify morphologically nonidentifiable specimens or fragments of specimens (Frézal $\&$ Leblois, 2008), which in this case were the remains of host larvae. This can help identify the hosts of parasitoids.

ACKNOWLEDGEMENTS. We thank K. Horstmann, M. Schwarz and K. van Achterberg for identifying specimens. S. Viinikainen performed the DNA extractions and the sequencing. We thank E. Knott and three anonymous reviewers for making valuable comments on earlier versions of the manuscript. This research was part of a project (no. 116892) funded by the Finnish Academy to AG, the Centre of Excellence in Evolutionary Research and the Ehrnrooth foundation to JAE.

\section{REFERENCES}

AKaIKe H. 1974: A new look at the statistical model identification. IEEE Trans. Automat. Contr. 19: 716-723.

BARRon J.R. \& BisDEE J.R. 1977: The final instars of Leptocamplex cremastoides and Macrus parvulus (Hymenoptera: Ichneumonidae: Campopleginae), and notes on the classification of the genera. Ann. Entomol. Soc. Am. 70: 290-292.

Bernardo U., Monti M.M., Nappo A.G., Gebiola M., Russo A., Pedata P.A. \& Viggiani G. 2008: Species status of two populations of Pnigalio soemius (Hymenoptera: Eulophidae) reared from two different hosts: an integrative approach. Biol. Contr. 46: 293-303.

Brower A.V.Z. \& DeSalle R. 1998: Patterns of mitochondrial versus nuclear DNA sequence divergence among nymphalid butterflies: the utility of wingless as a source of characters for phylogenetic inference. Insect Mol. Biol. 7: 1-10.

Charnov E.L. \& Skinner S.W. 1985: Complementary approaches to the understanding of parasitoid oviposition decisions. Environ. Entomol. 14: 383-391.

Desneux N., Starý P., Delebecque C.J., Gariepy T.D., Barta R.J., Hoelmer K.A. \& Heimpel G.E. 2009: Cryptic species of parasitoids attacking the Soybean aphid (Hemiptera: Aphididae) in Asia: Binodoxys communis and Binodoxys koreanus (Hymenoptera: Braconidae: Aphidiinae). Ann. Entomol. Soc. Am. 102: 925-936.

Diller E. 1988: Vorläufige Resultate einer Bearbeitung der Gattungen Hemichneumon Wesmael, 1857, und Trachyarus Thomson, 1891 (Hymenoptera, Ichneumonidae, Phaeogenini). Entomofauna 9: 369-380.

Dorchin N., Scott E.R., Clarkin C.E., Luongo M.P., Jordan S. \& Abrahamson W.G. 2009: Behavioural, ecological and genetic evidence confirm the occurrence of host-associated differentiation in goldenrod gall-midges. J. Evol. Biol. 22: 729-739.

Elzinga J.A., Grapputo A., Chevasco V. \& Mappes J. 2011: Influence of male mating history on female reproductive success among monandrous Naryciinae (Lepidoptera: Psychidae). Ecol. Entomol. 36: 170-180.
Elzinga J.A., Zwakhals K., Harvey J.A. \& Biere A. 2007: The parasitoid complex associated with the herbivore Hadena bicruris (Lepidoptera: Noctuidae) on Silene latifolia (Caryophyllaceae) in the Netherlands. J. Nat. Hist. 41: 101-123.

Folmer O., Black M., Hoeh W., Lutz R. \& Vrijenhoek R. 1993: DNA primers for amplification of mitochondrial cytochrome c oxidase subunit I from diverse metazoan invertebrates. Mol. Mar. Biol. Biotech. 3: 294-299.

Forbes A.A., Powel T.H.Q., Stelinski L.L., Smith J.J. \& Feder J.L. 2009: Sequential sympatric speciation across trophic levels. Science 323: 776-779.

FrÉzAL L. \& LebloIs R. 2008: Four years of DNA barcoding: Current advances and prospects. Infect. Genet. Evol. 8: 727-736.

Godfray H.C.J. 1994: Parasitoids. Princeton University Press, Princeton, NJ, 488 pp.

GoKHMAN V. 2007: Revision of the genus Trachyarus Thomson. Spixiana 30: 65-83.

Grapputo A., Kumpulainen T. \& Mappes J. 2005: Phylogeny and evolution of parthenogenesis in Finnish bagworm moth species (Lepidoptera: Psychidae: Naryciinae) based on mtDNA-markers. Ann. Zool. Fenn. 42: 141-160.

Hajibabaei M., Singer G.A.C., Hebert P.D.N. \& Hickey D.A. 2007: DNA barcoding: how it complements taxonomy, molecular phylogenetics and population genetics. Trends Genet. 23: 167-172.

Hebert P.D.N., Cywinska A., Ball S.L. \& DeWaard J.R. 2003: Biological identifications through DNA barcodes. Proc. $R$. Soc. Lond. (B, Biol. Sci.) 270: 313-321.

Horstmann K. 1970: Bemerkungen zur Systematik einiger Gattungen der Campopleginae. Nachr. Bayer. Entomol. 19: $77-84$.

HoRstMANN K. 1973: Nachtrag zur Revision der europäischen Diadegma-arten. Beitr. Entomol. 23: 131-150.

Kankare M., Van Nouhuys S. \& Hanski I. 2005: Genetic divergence among host-specific cryptic species in Cotesia melitaearum aggregate (Hymenoptera: Braconidae), parasitoids of checkerspot butterflies. Ann. Entomol. Soc. Am. 98: 382-394.

KING B.H. 1987: Offspring sex ratios in parasitoid wasps. $Q$. Rev. Biol. 62: 367-377.

King K.C., Delph L.F., Jokela J. \& Lively C.M. 2009: The geographic mosaic of sex and the red queen. Curr. Biol. 19: 1438-1441.

Kumpulainen T., Grapputo A. \& Mappes J. 2004: Parasites and sexual reproduction in psychid moths. Evolution 58: $1511-1520$.

LePidopterologen-ArbeitsgrupPe 1997: Psychidae - Sackträger. In: Schmetterlinge und ihre Lebensräume. Arten, Gefärdung, Schutz. Schweiz und Angrenzende gebieten Band 2. Pro Natura - Schweizerische Bund für Naturschutz, Egg, pp. $165-308$.

Linares M.C., Soto-Calderon I.D., Lees D.C. \& Anthony N.M. 2009: High mitochondrial diversity in geographically widespread butterflies of Madagascar: a test of the DNA barcoding approach. Mol. Phylogenet. Evol. 50: 485-495.

Meier R., Kwong S., Vaidya G. \& NG P.K.L. 2006: DNA barcoding and taxonomy in Diptera: a tale of high intraspecific variability and low identification success. Syst. Biol. 55: 715-728.

Meyer C.P. \& Paulay G. 2005: DNA barcoding: error rates based on comprehensive sampling. PLoS Biol. 3: 2229-2238.

Mitter K.T., Larsen T.B., De Prins W., De Prins J., Collins S., Weghe G.V., Safian S., Zakharov E.V., Hawthorne D.J., Kawahara A.Y. \& Regier J.C. 2011: The butterfly subfamily Pseudopontiinae is not monobasic: marked genetic diversity 
and morphology reveal three new species of Pseudopontia (Lepidoptera: Pieridae). Syst. Entomol. 36: 139-163.

PAlmQvist G. 2008: Psychidae, Säckspinnare [Psychidae, Bagworm Moths]. In Bengtsson B.A. \& Palmqvist G. (eds): Nationalnyckeln till Sveriges Flora och Fauna. Fjärilar: Käkmalar - Säckspinnare. Lepidoptera: Micropterigidae - Psychidae. [Encyclopedia of the Swedish Flora and Fauna. Lepidoptera: Micropterigidae - Psychidae.] Swedish Species Information Centre, Swedish University of Agricultural Sciences, Uppsala, pp. 492-557 (in Swedish, English abstr.).

PosadA D. 2008: jModelTest: phylogenetic model averaging. Mol. Biol. Evol. 25: 1253-1256.

Ramirez S.R., Nieh J.C., Quental T.B., Roubik D.W., David W., Imperatriz-Fonseca V.L., Vera L. \& Pierce N.E. 2010: A molecular phylogeny of the stingless bee genus Melipona (Hymenoptera: Apidae). Mol. Phyl. Gen. 56: 519-525.

Ratnasingham S. \& Hebert P.D.N. 2007: BOLD: The barcode of life data system (www.barcodinglife.org). Mol. Ecol. Notes 7: $355-364$.

Ronquist F. \& HuELSENBECK J.P. 2003: MRBAYES 3: Bayesian phylogenetic inference under mixed models. Bioinformatics 19: $1572-1574$.

RUBINOFF D. 2006: Utility of mitochondrial DNA barcodes in species conservation. Conserv. Biol. 20: 1026-1033.

SchWARZ M. \& Boriani M. 1994: Redescription of Gelis longulus (Hymenoptera: Ichneumonidae), a parasitoid of Ocnerostoma piniarellum (Lepidoptera: Yponomeutidae). Eur. J. Entomol. 91: 331-334.

Schwarz M. \& Shaw M.R. 1999: Western palearctic Cryptinae (Hymenoptera: Ichneumonidae) in the National Museums of Scotland, with nomenclatural changes, taxonomic notes, rearing records and special reference to the British check list.
Part 2. Genus Gelis Thunberg (Phygadeuontini: Gelina). Entomol. Gazette 50: 117-142.

SeEhausen O. 2004: Hybridization and adaptive radiation. Trends Ecol. Evol. 19: 198-207.

Smith M.A., Woodley N.E., Janzen D.H., Hallwachs W. \& Hebert P.D.N. 2006: DNA barcodes reveal cryptic hostspecificity within the presumed polyphagous members of a genus of parasitoid flies (Diptera: Tachinidae). Proc. Natl. Acad. Sci. USA 103: 3657-3662.

Smith M.A., Wood D.M., Janzen D.H., Hallwachs W. \& HeBERT P.D.N. 2007: DNA barcodes affirm that 16 species of apparently generalist tropical parasitoid flies (Diptera, Tachinidae) are not all generalists. Proc. Natl. Acad. Sci. USA 104: 4967-4972.

Song H., Buhay J., Whiting M. \& Crandall K. 2008: Many species in one: DNA barcoding overestimates the number of species when nuclear mitochondrial pseudogenes are coamplified. Proc. Natl. Acad. Sci. USA 105: 13486-13491.

Tamura K., Dudley J., Nei M. \& Kumar S. 2007: MEGA4: Molecular Evolutionary Genetics Analysis (MEGA) software version 4.0. Mol. Biol. Evol. 24: 1596-1599.

Wagener B., Reineke A., Lohr B. \& Zebitz C.P.W. 2006: Phylogenetic study of Diadegma species (Hymenoptera: Ichneumonidae) inferred from analysis of mitochondrial and nuclear DNA sequences. Biol. Contr. 37: 131-140

Yu D.S., Achterberg K. van \& Horstmann K. 2005: World Ichneumonidae 2004. Taxonomy, Biology, Morphology and Distribution. CD/DVD. Taxapad, Vancouver, Canada.

Zwakhals K. \& Elzinga J.A. 2009: Trachyarus borealis sp. n., a previously undescribed parasitoid of Psychidae in Finland. Mitt. Münch. Entomol. Ges. 99: 129-133.

Received October 1, 2010; revised and accepted May 5, 2011 